\title{
Pragmatic relations and word order in Chinese*
}

\author{
Randy J. LaPolla \\ Institute of History \& Philology, Academia Sinica
}

This is an offprint from:

Pamela Downing and Michael Noonan (eds) Word Order in Discourse

John Benjamins Publishing Company

Amsterdam/Philadelphia 1995

(Published as Vol. 30 of the series

IY'POLOGICAL STUDIES IN LANGUAGE, ISSN 0167-7373)
ISBN 902722921 X (hb.) / 9027229228 (pb.) (European) 1-55619-424-2 (hb.) / 1-55619-636-9 (pb.) (U.S.)
(1) Copyright 1995 - John Benjamins B.V.

No pant of this book may be reproduced in any form, by primt, photoprint, microfilm or any other means, without written permission from the publisher.

\section{Introduction}

In LaPolla 1990, I presented arguments to show that Chinese is a language in which there has been no grammaticalization of the syntactic relations "subject" and "object". This being the case, then syntactic relations cannot be what determines word order in Chinese. In this paper I will argue that, aside from a semantic rule that the actor of a verb, if expressed, must precede that verb, it is pragmatic relations (information structure) that are the main determinants of word order in Chinese.' Though writing about a situation that exists for French and Italian, in the following quote Lambrecht could have been talking about Chinese:

It is interesting to observe that the difference in the pragmatic status of the NP referent as being either already present in the universe of discourse or not is not only expressed by the choice of lexical vs. pronominal encoding but also by the position of the NP in the sentence ... We thus notice a series of correlations between (i) presence of a referent in the universe of discourse, pronominal coding. preverbal position and topic status, and (ii) previous absence of a referent, lexical NP coding, postverbal position and focus status. We may draw from these correlations the preliminary conclusion that certain pragmatic differences having to do with the contrast between the text-external and the text-internal world are formally reflected in the morpho-syntactic structure of the sentence. (Lambrecht 1986:38)

As Li and Thompson (1978:687) argue, "word order in Chinese serves primarily to signal semantic and pragmatic factors rather than grammatical relations such as subject, direct object, indirect object" (see also $\mathrm{Li}$ and Thompson 1981:19 for similar arguments). Much has been written about the importance 
of "topic" in Chinese (e.g. Li and "Thompson 1974a, 1976, 1981; Barry 1975; Tsao 1979), but the importance of pragmatic relations ("focus structure" - see definition below) in determining syntactic structure is not that well understood. What $\mathrm{l}$ explore then in this paper is focus structure and its grammaticalization in the word order patterns of Chinese.

In discussing information structure, I will generally follow the theory outlined in the work of Knud Lambrecht (1986, 1987, 1988, 1989, to appear). The concept of information structure presented there is an outgrowth of the Prague School notion of Functional Sentence Perspective, though it goes far heyond the simple concepts of "theme" - "rheme". We will discuss two aspects of information structure: focus structure and the cognitive properties of discourse referents.

In the following introduction, it is not my intention to develop a theory of information structure, as this has already been done by Lambrecht. I will here only be presenting a stmmary of those aspects of information structure (as presented in Lambrecht's work) that are relevant to Chinese. Please see Lambrecht (to appear), for a complete and detailed analysis of information structure.

The concept of focus structure, as defined in Lambrecht (to appear) will be the center of interest in our discussion of information structure:

Focus structure: A grammatical system used to mark the focus of the assertion in a sentence by setting it off against the pragmatic presupposition.

By "grammatical system" is meant a particular use of intonation, morphology, word order, special "constructions", or a combination thereof. We then need to define the terms pragmatic presupposition, assertion, and focus of the assertion:

Pragmatic presupposition: The set of propositions evoked in an utterance which the speaker assumes the hearer already knows or believes or is ready to take for granted at the time of speech.

Pragmatic assertion: The proposition which the hearer is expected to know or believe or take for granted as a result of hearing the utterance.

Focus (or focus of the assertion): That portion of a proposition whereby the assertion differs from the presupposition.
The pragmatic presupposition, a propositional notion, must be distinguished from the topic, which is the NP (expressed or not) within the pragmatic presupposition that has the function of naming the referent that the assertion is about. As the assertion includes both the presupposition (and the topic) and the focus, it is a pragmatically structured proposition, a proposition in context. It is not the case that every utterance has a topic (sec below), or that every sentence involves an explicit assertion (as with conventionalized polite greetings, etc.).

Focus structure is not a question of identifiable vs. unidentifiable NPs; it is "an indicator of a semantic relation holding on the level of the sentence or proposition as a whole, not ... an expression of information properties of individual sentence constituents" (Lambrecht 1989:3, emphasis in original). For Lambrecht, there is "a threefold distinction ... between information as conveyed by propositions, the pragmatic states of the referents of individual sentence constituents in the minds of the speech participants, and the pragmatic relations established between these referents and propositions" (to appear, p. 42, cmphasis in original) ${ }^{2}$

Lambrecht (1986, 1987, 1989, to appear) distinguishes three main types of focus structure: "predicate focus", "narrow focus", and "scntence focus". Predicate focus is statistically the most common of the three. It involves an assertion with an unmarked topic-comment structure. ${ }^{3}$ There is a topic that is within the presupposition; the domain (scope) of the focus is then the comment (predicate), and within this there is an unmarked focus position, usually the object position (see also Givón 1979b:51-53 on this last point). Lambrecht gives examples (1a-d) (1989:5), to which thave added the Chinese equivalent:

(1) Q: How's your car?

A: a. My car/it broke dow'

English (subject-predicatc)

b. (La mia macchina) si è rotta. Italian (subject-predicate)

c. (Ma voiture) elle est en panne. French (topic-subject-predicate)

d. (Kuruma w'a) koshoo-shi-ta. Japanese (topic-comment)

e. (Wo de che zi) huai le. Chinese (topic-comment)

In this structure, as the topic is part of the presupposition, it is usually not necessary for it to be explicitly stated for the assertion to be understood, so it is often pronominalized or, in the case of French, Italian, Japanesc, and Chinese, completely unexpressed (as shown by the parentheses around the topics).

Lambrecht"s second type of focus structure is the narrow focus or "contrastive focus" structure. In a narrow focus structure only a single NP is in 
focus; the rest of the assertion is within the presupposition, as in the examples in (2) ((2a-d) from Lambrecht 1989:8; the focused ND is in bold).

(2) Q: I heard your motorcycle broke down?

A: a. My car broke down. English (NP focus accent)

b. É la mia macchina che si è rotta. Italian (e-cleft)

c. C'est ma voiture qui est en panne. French (c'est cleft)

d. Kuruma ga koshoo-shita. Japanese (ga-marking)

c. Shi wo chezi huai le. Chinese (shi-cleft)

Just as it is possible to pronominalize or drop the topic of a predicate focus structure, it is often possible to leave out all but the focused constituent in a narrow focus structure. That is, a single NP could be the whole complete utterance, as in the answer to the question-word question in (3).

(3) a. Weiyuahlui xuan shei lai dang zhuxi? committe choose who come act-as chairman 'Who did the committec choose to be chairman?'

\section{b. Zhangsan}

(personal name)

Again it is important to cmphasize that the NP in focus is not necessarily "new information", as "it is not so much the focus noun itself which contributes the new information to the discourse but the relationship between (the referent of this noun and the cntire proposition" (Lambrecht 1989:9). In fact, "information is never conveyed by single words or expressions or even con" stituents, but by establishing relations between words as elements of propositions" (Lambrech 1986:160, emphasis in original). ${ }^{\text {s }}$

In Chinese, intonation can also be used to focus any constituent in the sentence (Teng 1985:166): predicate focus has the intonation on the predicate, and this is the unmarked case; narrow focus can be achieved by using marked intonation on the focused constituent. Therefore, (4), below, could be the answer to When did Miss Zhao ask for three days' leave of absence?, Who was it that last month asked for three day's' leave of absence?, or How many days leave did Miss Zhao ask for last month?, depending on whether the prosodic stress is placed on the temporal phrase, the actor, or the modifier of the final NP respectively (Teng 1985.).
(4) Zhao Xiaojie shang ge yue qing le san tian Zhao Miss last $\mathrm{CL}$ month ask-for AsP three day jia.

vacation

'Miss Zhao last month asked for three days' leave of absence.'

The third type of focus structure discussed by Lambrecht, sentence focus, requires little or no presupposition; the focus of the assertion is the entire sentence. This is the type of sentence referred to by Kuno (1972) as "neutral description" or "themeless". This type is semantically non-binary, as there is no topic-comment or focus-presupposition structure, and so is often referred to as thetic, as opposed to categorical (c.g. Sasse 1987). It is generally presentational, presenting either a state of affairs or a new referent (Sasse's "eventcentral" or "entity-central"). In languages that have syntactic subjects, the subject is the unmarked topic, so for a subject to be interpreted as not topical it must be "detopicalized", marked in some way, cillier by intonation, word order, or morphology. As the unmarked focus position is that of the object, most languages detopicalize the subject by giving it markings, intonation, or word order similar to those of an object (Lambrecht 1989:10).

(5) Q: What happened?

A: a. My car broke down. English (accented subject NP) b. Mi si d rotta la macchina. Italian (inverted subject NP)

c. J'ai ma voiture qui est en panne. French (clefted subject NP)

d. Kuruma ga koshoo-shi-ta. Japanese (morphol. marking)

Chinese does not have a grammaticalized subject or object, but the relevant NP (what otherwise might be interpreted as a topic) must still be shown to be nontopical in a sentence focus construction. B's answer in (6) is one type of sentence focus structure in Chinese.

(6) A: Fasheng le shenme shi? happen AsP what affair 'What happened?'

B: Gang lai le yi da dui liumang. just-now come Asp one big group hoodlum 'A group of hoodlums just arrived.'

In this example the "big group of hoodlums" is marked as non-topical by its postverbal position. It is then not a statement about the hoodlums, but merely asserts that the event of their appearance occured. 
One important point we can see from all the examples above is the different ways languages have of marking the different types of focus structure, which gives us a window on the interactions and precedence relations (which type of relation takes precelence over another) between syntactic. semantic and pragmatic relations. We sec that in English syntactic relations control the syntactic structure, and are relatively unaffected by pragmatic relations, while in Italian and French pragmatic relations take precedence over syntactic rclations in detcrmining syntactic structure. In Chinese pragmatic relations are not subject to syntactic factors, but take a back seat to semantics if the verb has an argument that is an actor (i.c. agent, effector). We will look at the different constructions involved below, but first we will look at the NPs involved in the constructions.

lollowing I will give a very brief outline of some of the different semantic properties and pragmatic statuses the representation of a referent may have in a discourse. This will be essentially to define the terms to be used in this paper rather than to explicate a theory of pragmatic categories. See lambrecht, to appear, Clapter 3 for such an explication (cf. also Du Bois $1980)$.

An NP is referential if the speaker intends for it to refer to a particular entity which exists within a particular universe of discourse, with continuous identity over time (cf. Givón 1978:293, Du Bois 1980:208). This referential NP will be either identifiable or unidentifiable to the addressee. If it is identifiable, it will be in one of three activation states, active (currently the focus of consciousness), accessible (not the current focus of consciousness, but textually, situationally, or inferentially derivable), or inactive (not in the focus or periphery of consciousness, but in long (erm memory). A referent will often be unidentifiable when first introduced into a discourse, but it can be introduced in two ways, either as a "brand-new" thanchored referent, or as an anchored referent (these terms from Prince 1981), one where the unidentifiable referent is presented as related in some way 6 an identifiable referent (as in a guy $I$ work with). Further mentions of a referent after its introduction will then treat it as identifiable. $A$ referential NP is specific if it is identifiable to the speaker, regardless of whether it is identifiable to the addressee or not. If the individual identity of the referent is not important to the speaker, it is non-specific (as in I'm looking for a mouse - - it could be one l just lost (specific), or any mouse I happen to come across (non-specific)). Genctics, predicative NPs, and nouns that occur in compounds (c.g. bear-fmuting) or are under the scope of negation are all non-referential. This gives us the hierarchy of referential Nl's (exclud-

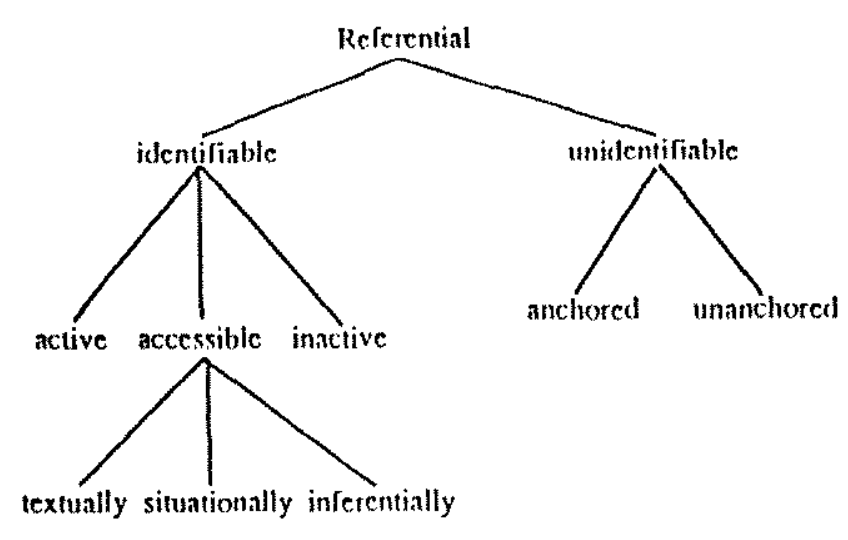

Figure 1. The cognitive states of referential NI's in discourse

ing the specific-non-specific contrast) as presented in Figure 1.

It is important to point out the difference between the (possibly universal) cognitive category of identifiability and the (language specific) grammatical category of definiteness. Definiteness can be said to be the grammatical coding of an NP as to whether or not the speaker assumes the referent of the NP is identifiable to the addressec, though this is a rough definition, as the relationship between definite coding, to the extent that it exists, and the cognitive statuses of referents varies greatly between languages.

It is also important to emphasize the distinction between the activation status of a referent and the information structure catcgories introduced above. The former involves the cognitive statuses of discourse referents, white the latter involves the relations between discourse referents and propositions.

\section{The question of "definiteness"}

The first question we will discuss is the types of codings NPs can have in Chinese in relation to their activation states, and whether or not word order is involved in marking "definiteness" or identifiability in Chinese, as is often assumed. Mullie (1932:160-168) outlined a correlation between "definiteness" (what he referred to as "determinateness") and preverbal position, and between "indefiniteness" ("indeterminateness") and post-verbal position, for the single argument of intransitive verbs. Mullie's analysis was quite insightful, as he 
saw that what determined word order for intransitives was not accurately captured by the use of the terms "icteminate" and "indeterminate" ("definite" and "indefinite"); he also understood the use of having the "subject" of intransitives in post-verbal position "when 'a state of affairs' or 'an action', thus the verb rather than the subject, is emphasized" (1932:166) (see below on the event-central thetic sentence); and he understood the possible (though not always necessary) use of the "circumlocution" of the presentative construction for "indeterminate" "subjects" of transitive verbs. (See below for discussion of the presentative constructions.)

Y. R. Chao (1968:76-77) stated that "there is a very strong tendency for the subject to have a definite reference, and the object to have an indefinite reference", but it is "... not so much the subject or object function that goes with definite or indefinite reference as position in an earlier or later part of the sentence that makes the difference". Teng (1975) and Zhu (1982) also give similar analyses. It is significant that each of these scholars stated the tendency with hedges; each recognized the weakness of the generalization. (For examples that violate this tendency (i.c., have "indefinite" sentence initial NPs) see Fan 1985.)

In Li and Thompson 1975, an altempt is made to formalize this relationship between word order and the "definiteness" of the NPs of a sentence in Chinese. They give the following "tendency" (p. 170):

Tendency A: Nouns preceding the verb tend to be definite, while those following the verb tend to be indefinite.

Tendency $\Lambda$ is an overgeneralization, so Li and Thompson propose a set of refinements (p. 184):

Refincment 1: The noun in postverbal position will be interpreted as indefinite unless it is morphologically or inherently or non-anaphorically definitc.

Refinement 2: $A$ sentence-initial noun nust be interpreted as definite, and may not be interpreted as indefinite even if it is preceded by the numeral $y i$ 'one'.

Refinement 3: The noun following bei, although pre-verbal, is immune to Tendency $\wedge$.

Refinement 4: Nouns in prepositional phrases are immune to Tendency A. ${ }^{8}$

Tendency $\wedge$ has been supported by data from quantitative discourse analyses of Chinese texts, such as Sun and Givón 1985 and M. Wang 1988.
Sun and Givón (1985) actually claimed to have disproved Tendency $\wedge$ with a quantitative discourse analysis of both written and oral texts, but Nichols (1988a) has shown that when run through the relevant statistical tests, Sun and Givón's own data support Tendency $\Lambda . \wedge$ similar study (M. Wang 1988) done with the same methodology used by Sun and Givon came up with results that also support $\mathrm{Li}$ and Thompson's hypothesis.

Though there is this tendency, Li and Thompson point out that

[t]here is by no means a strict correlation between the definite interpretation of a noun and its position relative to the verb ... [W]ord order plays a significant and systematic role in distinguishing definite from indefinite nouns, although it is not the only means by which definite and indefinite nouns may be distinguished from each other. (1975:184-5)

As $\mathrm{Li}$ and Thompson recognize in their discussion of Tendency $\Lambda$, there are two parts to the question of "definiteness" in Chinese: (1) the coding on the NP, and (2) what they consider to be coding by position of that NP' in the sentence. We will look at cach of these separately to see if they are really two parts of the same thing.

\subsection{Coding on the NP}

Each type of discourse referent in Chinese may be represented in several ways. A referent that is active will often be represented by a zero or overt pronoun, but can also be expressed as a bare lexical NP or one preceded by a genitive phrase or by a deictic pronoun (including a numeral plus classifer phrase if the number of the referents is important). ${ }^{9}$

(7) A: Zhangsan jintian lai guo ma?

Zhangsan today come ASP $Q$

'Has Zhangsan come (in) today?'

B: Ø, meiyou, keshi (ta) yi huir hui lai, lta de $\mathrm{N}-\mathrm{A}$ but $(3 \mathrm{sr})$ one time will come $3 \mathrm{sG}$ GEN chezil, you wenti.

vehicle have problem

'No, but he'll be in in a little while, his car has a problem.'

A: $\left(\left(/ T a_{i}\right.\right.$ de) chezil) you you wenti le! $\emptyset_{j}$ ((3SG GEN) vehicle) again have problem ASP

zhen shi lan huo.

really cop rotten goods

'His car has problems again! It's really a piece of junk.' 
In this example, Zhangsan is inactive (or accessible) in the first utterance, but after being mentioned is then active in the second utterance and so can be represented as a zero or a pronoun. His car is introduced as an inactive (or possibly anchored unidentifiable) referent in the second utterance, and is then active in the last utterance, so can be represented by the bare noun, the noun with the genitive phrase, or a zero.

$\Lambda$ referent that is accessible or inactive will generally be encoded as a bare lexical NP or one preceded by a genitive phrase or by a deictic pronoun (see ex. (7)). An unanchored unidentifiable referent which is to become a topic in the discourse will generally be introduced as a lexical noun preceded by a numeral (usually yi 'onc') plus a classifier

(8) Wo zuijin mai le yi shuang xiezi, keshi $\emptyset_{j}$ chuan

IsG recently buy $A \mathrm{SP}$ onc pair shoes but wear

le $\emptyset_{i}$ yi ci $\emptyset_{i}$ jin po le.

$\Lambda \mathrm{SP}^{3}$ one time then break $\mathrm{ASP}$

'I bought a pair of shoes recently, but only wore (them) once and (they) broke."

Here the shoes are introduced as an unanchored unidentifiable referent in the first clause, and are then active in the following two clauses.

An unanchored referential-tmidentifiable referent which is not to become a topic (is incidental to the discourse) will often either not have the numeral plus classifier, or will have the classifer, but not the numeral. ${ }^{10}$ An unidentifiable referent can also be introduced as an anchored referent, where it is marked as related, usually by a genitive phrase, to some other element either known to the addressee or within the schema or frame of the discourse, such as is the case with gongren 'worker' in the following example:

(9) Xuexias de $y^{i}$ ge gongren zuotian chu school GEN one CLASS worker yesterday produce ASP che-limo.

car-accident

'Yesterday one of the workers in the school got into a car accident,'

Non-referential NPs will be represented as bare lexical nouns or nouns preceded by a numeral plus a classifier or just a classifer:

$$
\begin{aligned}
& \text { (10) a. Ta shi ((yi) ge) gongren. } \\
& \text { 3sa cop ((one) (I,Ass) worker } \\
& \text { 'He is a worker.' }
\end{aligned}
$$

b. Bu guan cong nali lai, ren zong shi ren. not matter from where come person always cop person 'No matter where (they) are from, people are still people.'
c. Yi ge ren zai wuliao de shihouhui one CLASS person ASP uninteresting GEN time will xiang he jiu.
think drink liquor
'When a person is bored s/he will think of drinking liquor.'

In (10a), the predicative phrase 'a worker' can be coded in Chinese as a bare noun, a classifer plus noun, or 'one' plus classifier plus noun. In (10b), the generic 'person' is coded as a bare NP, while in $(10 \mathrm{c})$ it takes a numeral and classifer.

Following is a summary of the types of representations each type of referent may have:

\section{Type of referent}

Active

Accessible

Inactive

Unanchored Unidentifiable

Anchored Unidentifiable

Non-referential

\section{P'ossible codings}

zero, pronoun, bare NP, with deictic pronoun pronoun, bare NP. with deictic pronoun barc NI', with deictic pronoun bare NP, (numeral +) classifier genitive phrase, relative clause bare NP, (numeral +) classifier
From the point of view of the type of NP which represents a particular referent, we can see that Chinese can generallly distinguish between active and non-active identifiable referents by the use of zero anaphora for active referents, and between identifiable and unidentifiable referents by the use of a deictic pronoun as a modifier on nouns representing identifiable referents.

Chen (1986:16-17) considers all NPs marked with a genitive phrase or relative clause to be "definite" (so, for example, the topic in (9), which represents an anchored unidentifiable referent, would be considered by Chen to be "definite"), and only unanchored unidentifiable referents with overt marking (numeral plus classifier) as "indefinite". The fact that almost any type of referent can be represented by a bare noun with no overt marking leads Chen to posit a third grammatical category, which he calls "indeterminate". The pragmatic states of the referents of these "indeterminate" NPs, according to Chen, are interpreted by the addressec as "definite" or "indefinite" on the 
basis of "syntaclic or discourse contexts" (1986:19). Given these facts, and the fact pointed out by Chafe (1976:39) and Givon (1978:319) that since the deictic (demonstrative) pronouns do not lose their deictic force when used for "definitization" they cannot be seen as simply marking "definitization", 1 would argue that Chinese does not have a grammatical category of definiteness, but simply several means for expressing the pragmatic category of identifiability.

In terms of position of an NP in a sentence, there are few restrictions based on the semantic or pragmatic status of the referent of that NP. "Generic $(10 b-c)$, uniquely identifiable (1/a-b), and any overtly marked NPs (either definite or indefinite - (12a-d)) can appear before or after the verb, without a change in pragmatic status (Chen 1986:37; sce also the refinements to $\mathrm{Li}$ and Thompson's Tendency $\wedge$ given above) (The relevant items are in bold type; (12a) is from Fan 1985:322, originally from a New China News Agency bulletin.)

(11) a. Thiyang chu lai le.
sun
otit come ASP

'The sun has come ont.'

b. Wo yi zheng tian dou mei kan dao taiyang Is; one whole day all $\mathrm{N}-\Lambda$ look arrive sun 'I haven't seen the sun all day.'

(12) a. Liang ge Shaoxianduiyuan xiang $X u$ Haifenghe two Class Young-Pioneer(s) towards $\mathrm{Xu}$ Haifeng and Wang Yifu xian le xian hua he hong lingjin. Wang Yifu give Asp fresh flowers and red scarf. "I'wo Young Pioneers gave fresh flowers and red scarfs to $\mathrm{Xu}$ Haifeng and Wang Yifu.'

b. Laoshi jintian song wo yi fu huar. teacher today give 1 so one Class painting 'Today the teacher gave me a painting.'

c. Nei ge ren jimtian mei lai. that Class person today $\mathrm{N}-\mathrm{A}$ come 'That person didn't come today.' d. A: Che shang chule nei ge ren yiwai, vehicle on aside-from that CLAss person aside-from hai you shenme ren?

still have what person

"Who else is on the train aside from that person?"

B: Jiu zuo nei ge ren.

only sit that CuAss person

Only that person is sitting there.

It is only the indeterminate category that, according to Chen, is affected by position in a sentence (cf. Chao 1968:76):

(13) a. Lai le keren.

come Asp guest

'There came a guest.'

b. Keren lai le.

Guest(s) come $A S P$

'The guest(s) have come.'

Chen essentially follows the scholars mentioned above in assuming that word order determines "definiteness". Only Givon questions whether the preverbal word order patterns are

indeed 'mere definitization' or topic-shifting devices. The nouns occurring in them could be definite or generic, which is a general restriction holding to definite NPs as well as topic-shifting. The distributional restrictions in these word order devices in Mandarin, including the ba construction, strongly hint that they are topic-shifting rather than definitization devices. $(1978: 319)$

I propose that it is not identifiability that is coded by word order, but focus structure. If we look beyond the identifiability of the referents of noun phrases, we can see that Tendency $\Lambda$ is actually only one part of a more general tendency to have the focus at the end of the sentence (cf. note by Dragunov in Wang 1982:106; Huang and Davis 1988:9), or at least postverbal (in the case of cleft constructions). The confusion of focus structure with the representation of referents came about because referents newly introduced into the discourse will almost always occur in the sentence final (post-verbal) focus position (99\% of referential-"indefinite" NPs in Sun and Givón's study (1985) were post-verbal), so post-verbal position became associated with "indefiniteness". As a topic is most often identifiable, and as topic position is 
preverbal, preverbal position became associated with "definite" NPs. Yet an NP of any type of referentiality or identifiability can occur in postverbal position, if it is focal, and the same NP can occur in preverbal position, if it is topical. We can then make a much stronger generalization than Tendency $\mathbf{A}$, with all its refinements, $w$ : the much-hedged statements by other scholars, if we say that topical or non-focal NPs occur preverbally and focal or nontopical NPs occur post-verbally. ${ }^{12}$ In this generalization 1 include non-focal NPs with topical NPs because aside from topical NPs, which will generally be sentence initial, non-focal NPs (sccondary topics, non-referential NPs used adverbially, etc.) can also appear preverbally, albeit in non-initial position. 1 also include non-topical (including non-referential) NPs with focal NPs becatuse in a predicate focus structure a focal NP will appear postverbally to mark it as focal, while in an event-central thetic phrase a non-topical NP will appear post-verbally to mark it as non-topical (see below for examples). Focal and montopical ND's can both appear postverbally because they share the characteristic of $N O H$ being an entily lhat an assertion is predicated of.

\section{Marked focus constructions ${ }^{13}$}

Word order in Mandarin is "consistently" verb medial (Li and Thompson 1978) due to the statistical predominance of predicate focus sentences, but there are a number of constructions that deviate from this form because of the influence of marked focus structure. By "marked" I simply mean statistically less common. There is no such thing as a pragmatically "neutral" sentence; all sentences have focus structure, but one type, predicate focus, is more common, and so less "marked". In a language such as English, a sentence focus sentence can have the same syntactic structure as a predicate focus sentence, but the subject NP will not be topical and there will be no prosodic stress on the verb. In Chinese, a sentence focus sentence camot have the same structure as a predicate focus sentence. $\wedge$ presentative structure must be used to prevent a potentially topical ND' from being interpreted as a topic. Following we will examine both entity-central or event-central sentence focus structures, and discuss the focus structure of incorporation constructions.

\subsection{Entity-central presentative sentences}

Entity-central presentative sentences introduce a new referent into a discourse. They do this by placing the new referent in the postverbal focus position. ${ }^{14} \mathrm{Li}$ and Thompson (1981:509-519) classify these into two types. those which simply state the referent's existence or location (the "existential presentative sentence"), and those which introduce the referent with a verb of motion. This difference is exemplified in (14) ( $\mathrm{Li}$ and 'Thompson's (2) and (3), p. 509-10):

(14) a. (zai) yuanzi-li you yi zhi gou. (toc) yard-inside exist one CI.Ass dog 'In the yard there is a dog.'

b. Lai le yi ge keren. come AsP one Cinss guest 'There came a guest."

Sentences with the existential verb you, as in (14a) lave two possible structures, the one given in (14a) and that in (15) (Li and Thompson's (7), p. 511):

(15) You yi zhi gon äai yuanzi-li. exist one Class dog tor yard-inside 'There is a dog in the yard.'

$\mathrm{Li}$ and Thompson point out that there is a pragmatic difference between these two structures, but they see the difference in terms of the "definiteness" of the locus (yuanzi). That is, they state that for (14a) to be used properly, the locus must have already been established in the discourse context, as it functions as the topic of the sentence. Yet if we look at the identifiability of yuanzi, we see that in both (14a) and (15) the yard is in the same state of identifiability - it is jdentifiable (this is the unmarked state for locatives - Van Valin 1975); the "definiteness" of the yard then cannot be important here. What is different between the two is the focus structure. In (15) line yard is identifiable, so it is not being introduced as a new referent, as the dog is, yet it is focal (both clauses in (15) contain focal NPs). In (14a) ywamzi $l i$ 'in the yard' is not focal, but it is also not a topic about which an assertion is heing made. It merely acts as a locative reference point (it is situationally accessible); the locative serves simply to anchor the new referent in the discourse (Lambrecht 1988:15-16). It is generally not the topic of a topic chain, for example, or even simple cross- 
clause coreference:

(16) a. Yuanzi li you junren danshi $\emptyset_{i}$ bu duo. yard inside have soldier(s) but not many 'There are soldiers in the yard, but not many.'

b. *Yuanzi $l_{i}$ you junren, danshi $\emptyset_{i}$ you kuan, $\emptyset_{1}$ yard inside have soldier(s) but also wide you da. also big

Li Naicong (p.c.) points out that the following sentence, in which the locative scems to be the topic of a topic chain, is grammatical:

(17) Yuanzi li you junren, hai you ji liang yard inside have soldier(s) also have several CLAss tankeche, suoyi $\emptyset$ xiande hen yongii.

tanks so appears very crowded

'In the yard there are soldiers and some tanks, so it looks quite crowded.'

In this case, though, the topic of xiande hen yongi 'appears very crowded' cannot be yuamzi-li 'in the yard' with a locative sense, but must be yuanzi 'the yard' (or possibly yuanzi-li, with a nominal meaning, 'the inside of the yard'), as yuanzi-li with a locative sense is an abbreviation of zai yuanzi-li in the yard", with the locative verb zai. This difference is significant. In the sentence initial position of (17), yuanzi-li and zai yuanzi-li are both permissible, but replacing the zero anaphor before xiande hen yongi with zai yuanzi-li would be ungrammatical. (See also the discussion of (19) below.)

The second type (i.c. (15)), with the locus and presentative phrases reversed is not an existential presentative sentence like (14a), as assumed by $\mathrm{Li}$ and Thompson, but is actually an example of what $\mathrm{Li}$ and Thomson (1981:611618) call the "realis descriptive clause sentence", a two-clause structure's where a referent is introduced in the first clause, and then an assertion is made about it in the following clause (both of which are part of the same sentence; see below). ${ }^{16}$

A second point about $\mathrm{Li}$ and Thompson's analysis of existential presentative sentences is that $\mathrm{Li}$ and 'Thompson equate them with possessives (p. 513). In their analysis, the only difference between a sentence such as (14a) and (18) (Li and Thompson 1981:513, ex. (14)) is that (18) has an animate locus.
(18) Ta you san ge haizi.

3sg exist three CLASS child(ren)

'He has three children.'

Yet there is an important difference in focus structure between (18) and (14a). In (14a) the locus can take the locative verb zai; that is, it is a separate clause (of the type in a serial verb construction), and it can occur either before or after the you clause with no change in the truth value of the utterance. The sentence is a sentence focus sentence, $i . c$, there is no topic. In (18), $t a$ is not a separate clause, it is the topic about which the assertion is being made. It cannot occur after the you clause. This is a predicate focus sentence, therefore not of the same class of sentences as (14a). Guo (1990:24-25) distinguishes between existential structures and what he refers to as "possessive subject" sentences on the basis of whether there is a "positional" particle (in example (19b), $l i$ 'inside') in the sentence initial NP. Without the positional particle, the initial NP is a topic in a sentence that says something about what happened to that topic; with the positional particle, the sentence-initial NP is not a topic, it is simply the location of the event or entity. Guo gives the following examples:

(19) a. Ta si le yi ge erzi. 3 sG die ASP one CLAss son 'One of his sons died (on him).'

b. Tou li si le yi ge ren.

head inside die ASP one CLASS person 'Someone among the leaders died.'

This distinction is clearest when the sentence initial NP is a location, as in (20). Without a positional particle, the sentence initial NP is not a locative, as in the existential sentences, but is a topic in a possessor relation to the post-verbal NP:

(20) Dongwuyuan pao le yi zhi xiongmao. zoo run ASP one CLASS panda 'The zoo lost a panda (by its running away).'

A difference similar to that between (14a) and (18) obtains between sentences such as (14a) and those such as (21), which Li \& Thompson (1981:514, ex. (17)) also discuss as a type of presentative sentence in that it identifies or characterizes the pre-copula $\mathrm{NP}$, which they also consider a locus. 
(21) Waimian shi yi zhi gou. outside Col' one Class dog 'What's outside is a dog.'

c. Wo mai le yi jian yifu hen hao kan. IsG buy ASP one CLASS clothes very good look 'I bought a piece of clothing (that is) very good looking.'

For this sentence to be used properly, "the speaker must believe not only that the listener already knows about the locus but that s/he has some reason to be interested in it and in what it is or what it has or what it looks like" (p. 515). The type exemplified by (14a), on the other hand, simply predicates "the existence of the presented noun phrase at some locus in which the listener need not have had any interest" (p. 515).

Again we can see that these two types are very different in terms of focus structure, and that this is what determines the difference in meaning and usage. In (21), the fact that the pre-copula NP is under discussion is clearly part of the presupposition (cf. the quote in the preceding paragraph), and there is an assertion made about it. It also cannot occur at the end of the sentence. This latter type of sentence and the possessive structure (as in (18)) then are different from the first type of existential presentative sentence (as in (14a), (15)): the first type, similar to there sentences in English, is comprised of either a simple thetic statement asserting the existence of an entity in a particular location (1.5), or a biclausal sentence focus statement involving a statement about the existence of some entity and its location (14a); the other two sentence types are both single-clause sentences with clear topic-comment structures.

The second type of "existential presentative sentence" discussed by $\mathrm{Li}$ and Thompson (1981:611-618) (and mentioned just above), they call the "realis descriptive clause sentence". This type is a serial verb construction in which a referent is introduced in the postverbal position of the first clause, then an assertion about the referent is made by the second clause ( $\mathrm{Li}$ and Thompson say that an "incidental description" is made of the NP by the second clause). The two clauses together are one intonation uniu/sentence. (Ex. (22b) is their (75), p. 611):

(22) a. (Waimian) you yi ge ren xiang jian ni. (outside) have one Class person think see 2 so 'There's a person (outside) who wants to see you.'

b. Ta you yi ge meimei hen xihuan kan 3sG have one CLASS younger-sister very like look dianying. movic

'S/He has a younger sister (who) likes to watch movies.'
In all of these examples the structure is a juncture of two clauses, but (22a) does not have exactly the same focus structure as $(22 b)$ or $(22 c)$ : (22a) has a simple presentational clause, which asserts the existence of an entity, as discussed above, followed by a predication. The first clause simply allows the referent to become aclive in the discourse; the second clause makes an assertion about it. ${ }^{17}$ In (22b), on the other hand, there are two topic-comment type assertions, one about the topic $a$, the other about the sister that is introduced in the unmarked focus position of the first clause and becomes the topic of the second clause. The same structure can be assigned to $(22 \mathrm{c})$. It might be argued that in all three of these examples the first clause functions only to introduce a referent, yet the first clause is making an asscrtion about a topic (c.g., in (22c) that the topic ' $\mathrm{I}$ ' bought an item of clothing), cven if the proposition expressed is a rather uninteresting or uninformative one. The varicty of verbs that can occur in the first clause of this type of construction would also argue against seeing that clause as propositionally empty.

The nature of this type of structure in English is discussed at length in Lambrecht 1988. Lambrecht (1988:15) calls this structure a "presentational amalgam construction". An cxample of this in English is 1 have a friend of mine in the history department teaches two courses per semester (Lambrecht 1988:1), a construction usually considered ungrammatical in English, but nonetheless used very often. It is a structure where the speaker wishes to express a proposition about a referent being introduced, but is forced by the constraints on information structure (cf. Chafe's (1985:18; 1987:32) "One New Concept at a Time Constraint") to code the proposition in two clauses. The most efficient way to do this with a minimum of syntactic paraphrasing is to code the new referent simultaneously as the focus of the first clause and the topic of the following clause. Sasse (1987:541 ff.) also discusses similar structures in Arabic, Boni and other languages.

This is a type of core-coordination where the two cores share an argument. ${ }^{18}$ The struclure created, then, is lighter than simple juxtaposition. Though I talk about the referent being introduced in the first clause of a realis descriptive clause sentence and then having an assertion made about it, this is not a two-step process; it is not a case of equi-NP deletion in the second clause. The single argument is actually shared by both cores, and so is both new and a topic. 
Li and Thompson point out the semantic similarity between these structures and relative clauses, ${ }^{19}$ and explain the difference in the following quote:

IT The message conveyed by the realis descriptive clause is that the property it names is entirely incidental, while the message conveyed by the relative clause is that there is a precstablished class of such items. By preestablished we mean that the item with the property in question is assumed or has already come up at some poim in discussions between speaker and hearer; they can be said to have tacitly agreed on the existence of a class of items with this property. (1981:614)

It would seem from this quote that they are talking about identifiability. They give the examples in (23) (their (84), p. 614) as evidence of the semantic difference between realis descriptive sentences and sentences with relative clauses:

(23) a. Wo mai le yi jian yifu tai da. Isc buy ASP one cusss clothes too big "I bought an outfit that lumed out to be too big."

b. Wo mai le yi jian tai da de yifu.

ISG bUy ASP one CLASS too big REL clothes

'I bought an outfit that was too big.'

They discuss the difference between these lwo sentences as one of whether or not there is a preestablished class of clothes that are too big. Yet the discourse status of the class of the referent is not what is important here. New information may be presented in the presupposed format of a restrictive relative clause as long as it is relatively unremarkable information, i.e. not the focus of the assertion (Du Bois 1980:223; see also Cumming 1984:369). What is important is that in (23a) an assertion is being made about the clothing, that it is too big. No such assertion is being made in (23b). That is, in (23a) there are two assertions, that I bought a picce of clothing, and that it is too big; in (23b) there is only one assertion, that I bought a piece of (a particular type of clothing. If anything is incidental, it is the information in the relative clause, not the information which is being asserted. Though it is not clear from the main body of their discussion, $\mathrm{Li}$ and Thompson clearly understand this point, as in the last few lines of the section they state that "semantically, a descriptive clause simply adds another assertion to the first one. A relative clause, on the other hand, is a part of the noun phrase naming the item in question, so it is natural that it allows the expression of a preestablished class of items with the property it names" (p. 618).
We now turn to presentative sentences which involve a verb of motion. In this construction, the new referent occurs immediately after the verb of motion (Li and Thompson 1981:517-19), such as we saw in (14b), repeated here:

(14) b. Lai le yi ge keren. come ASP one CLASS guest 'A guest came.'

This type of structure cannot be used with all intransitive verbs of motion, though; verbs such as gun 'roll', and pa 'climb' used alone cannot introduce a referent. They must be in a construction with another clause, as in exx. (14a) and (15), or appear in construction with presentative verbs that act as complements of result, as in (24):

(24) pa chu lai le yi zhi laohu. climb exit come ASP one ClAsS liger

'A tiger climbed out."

$\mathrm{Li}$ and Thompson do not give a reason for this difference, but what seems to be going on involves two different semantic factors. One is the aspect of the verbs involved: only a verb that is temporally bounded can be presentative (cf. Kuno 1972:300). The other factor is the meaning of the verbs involved: verbs such as pa 'climb' cannot introduce a referent because they are making a predication about the referent, whereas the general movement verbs, such as lai 'come', qu 'go', chu' 'exit', ctc. are semantically weak enough (they do not say anything about low the movement is done) that they can be used for presentational purposes. The latter, but not the former, also involve a directional component which naturally lends itself to the introduction of new referents. Lambrecht (1989:29) suggests that verbs such as 'arrive' are refentational due to their "inherent lexical content", and verbs such as 'call' may be construed as presentational because of the context. Du Bois $(1987: 836)$ also argues that intransitive verbs have two functions: introducing referents and adding semantic material, the difference depending on the discourse. 20

\subsection{Event-central thetic sentences}

In "event-central" presentative sentences, what is being asserted is the existence (happening) of an event, not the existence of an entity, so this type of 
structure will often not include referentially specific NPs. It is possible to have a referential NP in this type of structure, but it will be "pragmatically non-referential" (Givón 1981), that is, a referential NP can be treated as nonreferential when it is not salient in the discourse (see ex. (26a)). The prototypical examples of the "cvent-central" sentence are statements about the weather, such as $I t$ 's raining. In Chinese the verbs for rain and snow do not incorporate the object as in English, though the NPs 'rain' and 'snow' in the sentences in (25), below, are not referentially specific (do not refer to some specific rain or snow - are "non-manipulable" in the framework of Hopper and Thompson 1984, 1985), and not topical, and so are placed in postverbal position:

$$
\begin{aligned}
& \text { (25) a. Xia y'u le. } \\
& \text { fall rain } \mathrm{sp} \\
& \text { 'Il's raining.' } \\
& \text { b. Xia xue le. } \\
& \text { fall snow } \mathrm{sP} \text { ' } \\
& \text { 'II's snowing.' }
\end{aligned}
$$

This type of sentence is sometimes referred to as a type of existential sentence (e.g. Huang 1987), but the pragmatic function of these constructions is not to introduce a new referent; the NP which follows the verb is treated as non-topical, regardless of its identifiability.

An event-central expression can also appear as the comment in a topiccomment structure. In these cases, generally the topic is the possessor of, or is in some way related to, the NP' in the event-central expression. We can see the difference between event-central comments about a topic and an unmarked predicate focus structure from the examples in (26):

$$
\begin{aligned}
& \text { (26) a. Ta si le fnqin. } \\
& \text { 3sa die ASP father } \\
& \text { 'His father died.' } \\
& \text { b. Ta de fuqin si le. } \\
& \text { 3SG GEN father die ASP } \\
& \text { 'His father died.' }
\end{aligned}
$$

(26a) involves "possessor ascension", and is an example of what is often referred to as an "adversative" construction. The topic has no active control over the action represented by the verb (Guo 1990:27). A better translation for this sentence would be lle was affected by the death of (his) father. What gives the sentence this adversative reading is the fact that 'father' is made non-topical, by being placed in postverbal position, so that the dying of the father can be expressed as an event-central statement, which is then the assertion about the topic (cf. Kuno's (1987:206) concept of "empathy", the speaker's identification with the person or thing affected by the event being articulated). On the other hand, $(26 b)$ is a predicate focus statement about the topic 'his father', who died.

This structure is also possible with proper names appearing in postverbal position, as in the following example, which could be the brigade-leader's response to his superior's request for information about how the battle went, and could not be interpteted as a statement about Zhangsan and Lisi:

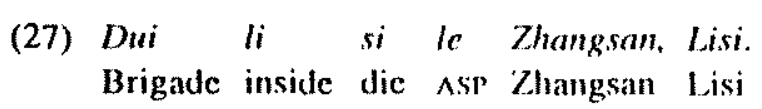

'In (our) brigade Zhangsan and Lisi dicd.'

The unitary nature of the event central phrase is evident in one type of aspectual marking that can appear with these structures. In general, noniterative achievement verbs such as si 'dic' lan ' $\mathrm{rot}$ ', and chen 'sink' cannot appear with the "experiential" aspect marker gwo, yet when these verbs appear in event-central utterances, they CAN take gwo (Guo 1990). This is because of the verb + post-verbal non-specific NP together being seen as one repeatabie event, as in the following example, from Guo (1990:26) (see also the discussion of the use of the adverb you 'again' in this type of structure in Teng 1974):

(28) a. Ta si guo yi pi ma. 3sg die ASP one CLASS horse 'One of his horses died (on him).'

b. Ta lan guo wushi jin xiangjiao. 3sG rol ASP fifty catty banana 'Fifty catties of his bananas rotted (on him).'

Contrast these with the following unaccptable examples, in which the preverbal NP must be interpreted as the topic of the verb and therefore can only experience the action of the verb once:

(29) a. *Ta you yi pi ma si guo. 350 have one Class horse dic ASP '(He has a horse that died (lit.: has experienced dying).)' 
b. *Ta you wushi jin xiangjiao lan guo. 3si have fifty catty banana rot Asp '(He has fifty catties of bananas that rotted (lit.: have experienced rotting).)'

Because of this unity of the verb + post-verbal NP, this structure is the pragmatic equivalent of noun incorporation. In languages with grammatically marked incorporation, incorporation of a subject noun into an intransitive verb converts a simple categorical (topic-comment) judgement into a thetic statement, and incorporation of a subject or object noun into a transitive verb can convert a double categorical (topic-comment within topic-comment) judgement into a simple categorical statement (Sasse 1984:260). In Chinese there is no marking of incorporation other than word order and possibly intonation, but the pragmatic effect is the same (see below for more on pragmatic incorporation).

There are examples of postverbal NP's that are identifiable in structures that look like presentational structures, but these are actually event-central constructions, as in (30) ( $\mathrm{Li}$ and Thompson's (30), p. 517), where the postverbal NPs are proper names:

(30) Women de wamhui zhi lai le Zhangsan gen Lisi. IPL GEN party only come ASP Zhangsan and Lisi 'Only Zhangsan and Lisi came to our party.'

McCawley (1988:7) considers the postverbal NP in this example as "indefinite" because he feels that the NP is the "focus" of the adverb zhi 'only", so "the meaning of such a combination is that of an "indefinite' NP: zhi ... Zhangsan means 'no one but Zhangsan'". L. Li (1986:350) also claims that the NP following $z h i$ 'only' must be "indefinite" ( $w w$ ding). The problem here is distinguishing between a referent's discourse status (identifiability) and information structure: $i t$ is true that the NP is being treated as non-topical, but being non-topical does not mean it is necessarily "indefinite".

This event-central construction also appears in background or scenesetting clauses (examples from Huang 1987:242):

(31) a. Suiran lai le Lisi/nei ge ren, keshi... although come ASP Lisi/that CLASS person but 'Although Lisi/that person has come, ...' b. Ruguo fasheng zhe jian shiqing, jiu ... if happen this Cl.Ass alfair then 'If that happens, then ...'

c. Zicong zou le Zhangsan yihou, jiu... from go ASP Zhangsan after then 'Ever since Zhangsan left, ...'

In these examples the post-verbal referent is identifiable, but it is not focal in the way that Zhangsan is in (30) (it is not contrastive). It is also not a topic. In adverbial clauses such as these, the proposition is pragmatically presupposed; there is no predication in the information-conveying sense of this word. The predicate then is not to be construed as being about the postverbal NP; the postverbal NP is presented as part of an event, and the event is simply background information for the assertion to come, as shown by the subordinating (relational) conjunctions.

\subsection{Pragmatic incorporation}

NPs that are not crucially involved in the assertion, that is, that are not topical or focal, can also appear in constructions where they act as modifiers of the verb (and so are within the comment), as is the case with the instruments incorporated into the verbs in (32):
(32) qiang-bi gun-kill
huo-shao fire-burn
'kill with a gun' 'burn with fire'
kou-shi
mouth-test

The type of NP in this construction is preverbal but non-topical. We can see from this that simply being in preverbal position does not make an NP "definite", nor does it make it a topic. The fact that it is non-referential may preclude it from being "definite", but it does not preclude it from being a topic, nor does not being in sentence initial position preclude it from being at least a secondary topic (sce the discussion of (33) below). It is simply the semantics of the combination, and the lack of any possible relevant topiccomment association that leads the hearer to infer an instrumental meaning for the preverbal NP.

A different type of pragmatic incorporation is the double nominative (Teng 1974) (or possessor ascension - Fox 1981) structure. This structure 
incorporates a comment about a body part and the body part itself into a comment about the possessor of the body part. As body parts are "universally not conceived of as discourse characters or as independent entities about which information is given during a conversation" (Sasse 1987:571), ${ }^{21}$ the body part is pragmatically incorporated into the comment, and the possessor of the body part becomes the topic about which the comment is made. ${ }^{22}$

$$
\begin{aligned}
& \text { (33) a. Wo duzi e le. } \\
& \text { Iso belly hungry ASP' } \\
& \text { 'I'm hungry.' } \\
& \text { b. Wo tou teng le. } \\
& \text { lso heal hurt } \wedge \text { ' } \\
& \text { 'I have a headache.' }
\end{aligned}
$$

In this type of double-topic construction, the main topic (" $1 \mathrm{sg}$ ' in both examples) is scmantically the possessor of the secondary topic ('belly'/'head'), but it is not grammatically marked as such, as the secondary topic has been incorporated into the comment about the main topic. There is also a comment about the secondary topic. ${ }^{23}$ There are structures where a topic-comment structure is itself an assertion about a more salient topic; that is, constructions exist that function to delincate primary from secondary topics, where the secondary topic is part of the assertion about the primary topic (cf. Tsao's (1987) treatment of the ba construction).

Lambrecht (1989) argues that a sentence such as My stomach hurts is a sentence focus structure because the subject noun is marked as a non-topic by its prosodic stress, which is ustally associated with objects. In Chinese. though, this proposition is not expressed in a sentence focus structure, but in the type of predicate focus structure involving pragmatic incorporation of the body part. In the English form of this proposition, the first person referent is not set off as a separate topic (it simply modifies the subject), but semantically it could also be said to be a statement about the first person referent. In Chinese this is simply made explicit.

\section{Conclusions}

What I have tried to show in this discussion of word order in Chinese is that (a) verb medial word order has the function of distinguishing topical or nonfocal NPs from focal or non-topical NPs, not "definite" and "indefinite" NPs. and (b) constructions have developed in Chinese which allow the topical (non-focal) and focal (non-topical) clements in marked focus structures to be clearly distinguished. In short, I would argue that in order to understand syntactic structures in Chinese, we need to make clear the role of pragmatic and semantic relations, and the interactions between them, in determining those structures.

\section{Abbreviations used in glosses}

LOC= locative verb; $N-A=$ negative aspect marker; $N O M L Z R=$ nominalizer; for further abbreviations, see list on $\mathrm{pp}$. ix.

\section{Notes}

l owe a great debt of gratitude to lvy Cheng, Derek Herforth, Knud Lambrecht, Mark V. LaPolla, Naicong Li, Tsong-hung L in, Ching Ching Lil, James D. McCawley, James A. Matisoff, Johanna Nichols. Tian-shin Jackson Sun, Sandra A. Thompson, Robert D. Van Valin, Jr., and the editors of this volume for their very helpful comments on carlier drafts of this paper. The exampies, unless otherwise matked, are from asking native speakers, given a particular context, what would be a natural utterance in that context.

1.. Cf. Conrie's (1981:72) analysis of Russian word orter, which he says is pragmatically determined (with the focus at the end), and unrelated to syntactic functions, and Sasse's (1981) analysis of Boni, a language of the Eastern Cushitic group, which also has pragmatically determined word order.

2. 'Cf. Kuno's division of information into two different concepts: "the concept applied to lexical items, on the onc hand, and the concept applied to the particular semantic relations which lexical items enter into in the given sentence" (Kuno 1972:272).

3. "By 'unmarked" here I mean the statistically most common type of sentence, where the comment follows the topic without involving a cleft or other type of 'marked' construction.

4. (2e) would be the equivalent of a "stressed focus it-cleft". An example of what would be an example of the equivalent of a wh-cleft (contra Teng 1979), as defined in Prince 1978 is (i):

(i) Wo mei mai de shi cai.

1sG N-A buy NOMLZR COP vegetables.

'What I didn't buy was vegetobles.'

As Prince points out, "though the it-cleft presents information (old vs. new) in an aberrant order, it clearly marks which is which" (1978:897). 
5. This clearly goes beyond the defirition of "new" information in Chafe 1974:112 as that which is "assumed nol to be in the addressec's consciousness". It is closer to the concept of "added information" in Clafe 1987, but it secuns for Chafe (and also Comrie 1981:56) "new information" is often simply a "new" constituent.

6. 1 did not use an example exaclly paraltet to the ones in (5) because the presence of the first person proneun and the semantics of the argument in the example complicate the point 1 am trying to make. These complications are discussed in Section 3 .

7. It is possible to consider that with generics the questions of referentiality and identifiability are neutralized, due to the fact that they are unindividuated, as are non-referential NPs, but at the same time can be topical, as if they were referential (Givon 1984:413). For the purposes of this paper I will treat them as non-referential NPs.

8. The need for at least two of these refinements was due to $\mathrm{Li}$ and Thompson's carlier analysis (cf. $I i$ and Thompson 1974b) of bei. zai, and other phrase-forming morphemes as prepositions. If instead we recognize (as $\mathrm{Li}$ ind Thompson themselves do in later papers) that these morphemes, which in Old Chinese, and in some cases also in Modem Chinese. are verbs, are still not completely grammaticalized, we can do away with Refinements 3 and 4

9. For examples other than those given here, see Givón 1978. Xu 1987, and Chen 1986. See Xu 1987 also for discussion of the correspondence of zero form in Chinese with forms marked by the definite article or definite pronoun in English.

10. See C. Sun 1988 for a discourse based study showing that there is a tendency for the representation of a referent which is "thematically important" to have the numeral plus classifier phrase when that referent is first introduced into the discourse, and for the representation of a referent which is not "thematically important" to not include the ntmeral plus classifier phrase; sce also Lambrecht, to appear, p. 67, for cross-linguistic evidence of the numeral plus classifier vs. plain classifer strategy

11. As mentioned in the Introduction, it is necessary to separate the pragmatic status of the referent of the NP in the mind of the speakethearer from the pragmatic relations that the $\mathrm{NP}$ is involved in.

12. Sec Lambreclu, to appear, p. 69 . for a similar analysis of Czech. Lambrecht also cites Arabic, Russian. Amharic, Turkish, Japancse, Fimnish, and Hungarian as languages where a claim (hy lletzron 1975) of correlation hetween preverbal definite marking and postverbal indefinite marking in locative sentences is "unwarranted"

13. Due to space limitations, only sentence focus stnuctures will be discussed here. A number of other word order patlems are dealt with in LaPolla, in preparation.

14. It is not necessarily the case that all new teferents are introduced with one of the following presentative constructions. Herring (1989) argues that (at least in the languages she looked at) new referents are often introduced in verbless presentational utterances. Naicong $L i$ (p.c.) has suggested that there may be a difference between those referents introduced in presentative constructions and those not introduced in presentative constructions in terms of their viability as topics in the following discourse. Both of these questions can only be solved by reference to a sizable discourse database, which at the present time is unavailable to me.
15. The juncture here is actually on a level lower than the clause, and a type of nexus different from both coordination and subordination. giving us what has often been called a serial Irom both eorion. See the discussion below of example (22), and particularly note 18.

16. With prosodic stress on yuanzi, this could also be a contrastive narrow focus construction, but then the 'one dog' would mean one dog ont of n number of dogs introluced in the preceding discourse.

17. This where we can see the interaction of semantic and pragmatic factors. If is necessary to use this construction in this case, rather than the "inversion" type as seen in (14b), to use this cor verb 'think' as opposed to the because the argument in for 'verb, the undergoet of the predicte 'nrived', Since an actor inust alus biclausal construction allows the focal actor to hoth appear in the focal position of the you
clause and still be in its proper preverbal position vis-a-vis xiang.

18. See Van Valin 1984, 1993 for discussion of juncture and nexus types, and llansell 1993 for See Van Valiscusion of some jestially, a CORE is the verb and a discussion of some juncture-nexus types in Chinese. Essentially. a CRRE is the verb and its direct arguments, and does not include the entire clause; corrdination is a juncture lype cosubordination (non-embedded but dependent) and subordination (embedded).

19. Tai 1973:661-663 in fact posits this form as the "underlying" form for all relative clauses Lambrecht (1988) treats the second clatse in this type of construction as a type of relative clause which is a sister to the first clause, whereas Sasse (1987:541) considers all relative clase when so believes the second clause is not a relative or some other non-finite to be non-finite. clause, but is a finite clause in a loser apro in the following attested example (from $\mathrm{H}$. There are cases
Sun 1982:297):

(i) Zang-Mian yuzu thong hai you xuduo zhongyao ywyin

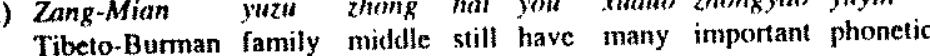
Tibeto-Burman family middle still have many
xianxiang qi genywan zhide tantao.

phenomenon GEN origin deserve investigation

In the Tibeto-Burman languages there are many phenomena whose origins are worthy of investigation."

This example differs from the earlier examples in the inclusion of the phrase qi genyuan 'GEN origin', which makes this look very much like a post-hend relative, something that Chinese supposedly does not have!

20. Expressed in the form of a decompositional semantic representation, lai-le 'come, arrive' would be [ 8 ECOME be-at' $(x)]$, where $x$ is a theme (the predicate being a stative verb).

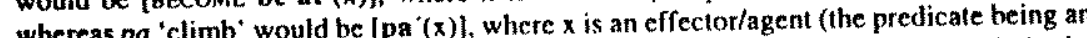
Whereas pa cling enty in the activity verb). As eflection with $p^{\prime}$ 'climb" it is a combination structure in (24) can the arguthe status, which then allows the of the [wo predicates, the state predicate providing the theme su (see Van Valin 1993 for argument to appear postverbaliy: (pa $(x)$ вFCOME
discussion of this type of semantic decomposition).

21. See also Hopper and Thompson (1984, 1985) on the "low catcgoriality" (as nouns) o See also Hopper and Thompson (1984, 1985) on the "low categoralits. Though they are as referential as the person to whom they belong. "in the discourse body parts are not in general autonomous, discou "are treated in grammar and discourse as dependent, non-individuated entities" (1984:726, 1985:167, emphasis in otiginal). 
22. Nichols (1988b:22) sees possessor ascension as the promotion of the possessor to argumenthood in the clause (the ascended possessor no longer forms an NP with the
possessed nown), which makes it a dependent on the verb nther then on the postessed moun. It then becomes a clausal, rather than phrasal, possessive pattern. Givon (1979b:91) meen. it then becomes a clausal, rather than phrasal, possessive pattern. Givon (1979b:91) sees it simply as fopicalization of the possessor because it is a more topical NP. The only ascension from the point of view of the ascended pols is whether we look at possessor noun.

23. See Teng 1974 for arguments why the sentence initial NP is a distinct topic not in the same NP as the affected body part and why the secondary topic should be seen as incorporated into the predication about the primary topic.

\section{References}

Barry, Roberta. 1975. "Topic in Chinese: An overlap of meaning, grammar, and discourse function." Papers from the Parasession on Functionalism, 1-9. Chicago Linguistic Society.

Chafe, Wallace L. 1974. "Language and consciousness." Language 50.111-33.

Chafe, Wallace L. 1976. "Giveness, contrastiveness, definiteness, subjects, point of view." C. N. Li, cd. 1976.27-55.

Chafe, Wallace L. 1979. "The flow of thought and the flow of language" Givon, 1979.159-82.

Chafe, Wallace L. 1985. "Information flow in Seneca and English." Proceedings of the /1th Annual Meeting of the Berkeley Linguistics Society, 14-24.

Chafe, Wallace L. 1987. "Cognitive constraints on information flow." Coherence and Grounding in Discourse ed. by Russell S. Tomlin, 21-52. Amsterdam/Philadelphia: John Benjamins.

Chao, Yuen Ren. 1968. A Grammar of Spoken Chinese. Berkeley: University of California Press.

Chen, Ping. 1986, "Referent Introducing and Referent Tracking in Chinese Narratives." PhD dissertation, UCl.A.

Comrie, Bernard. 1981. Language Universals and Linguistic Typology. Oxford: Blackwell, and Chicago: University of Chicago Press.

Cumming, Susanna. 1984. "The sentence in Chinese." Studies in Language 8.365-395.

Du Bois, John W, 1980. "Beyond definiteness: The trace of identity in discourse" Pear Stories ed. by Wallace Chafe, 203-74. Norwood, NJ: Ablex.

Du Bois, John W. 1987. "The discourse basis of ergativity." Language 63.805-55

Fan, Jiyan. 1985. "Wuding NP' 7huyu Ju (Sentences with indefinite NP subjects)." Zhonggwo Kuwen 1985.321 328 ,

Fox, Barbara. A. 1981. "Body part syntax: Towards a universal characterization." Studies in Language $5.323-342$

Givón, T. 1978. "Definiteness and referentiality." Universals of Human Language. Vol. 4: Symax ed. by Joseph II. Greenberg, 291-330. Stanford: Stanford University Press. Givón, T., ed. 1979a. Discourse and Symtax. New York: Academic Press. ISymar and Semantic, 121
Givơn, T. 1979b. "From discourse to syntax: Grammar as a processing strategy." In Givon, ed. 1979n.81-112.

Givón, T. 1981. "Logic vs. Pragmatics, with natural langunge as the referee." Journal of Pragmatics $6.81-133$.

Givón, T. 1984. Syntax: A Functional-Typological Introduction. Vol 1. Amsterdam/Philadelphia: John Benjamins.

Guo, Jimao. 1990. "Ling Zhu Shu Bing Ju (Sentences where the subject possesses the object)." Zhongguo Yuwen 1990.24-29.

Hansell, Mark. 1987. "Serial verbs and complement constructions in Mandarin: $A$ clause "linkage analysis." Davis Working P'apers in Linguistics 2.38-54. Reprinted in Advances in Role and Reference Grammar ed. by Robert D. Van Valin, Jr. Amsterdam and Philadelphia: John Benjamins.

Hansell, Mark. 1993. "Serial verbs and complement constructions in Mandarin; a clause linkage analysis." Advances in Role and Reference Grammar ed. by Robert D. Valin, 1) Jr, 197-234. Amsterdam/Philadelphin: John Benjamins.

Herring Susan C. 1989. "Verbless Presentation and the Discourse Basis of Ergativity." Papers from the 25th Regional Meeting of the Chicago Linguistic Society, Part II: Parasession on langunge in Comtext, 123-37. Chicago: Chicago Linguistic Socicty. Hetzron, Robert. 1975. "The presentative movement, or why the ideal word order is

y. V.S.O.P." Word Order and Word Order Change ed. by C. N. Li, 345-88. Austin: University of Texas Press.

Hopper, Paul J. and Sandra $\AA$. Thompson. 1984. "The discourse basis for lexical categories in Universal Grammar." Langinge 60.4:703-52.

Hopper, Paul J, and Sandra A. Thompson. 1985. "The iconicity of Noun and Verb". Iconicity in Syntax ed. by John Haiman, 151-83. Amsterdam/Philadelphia: John Benjamins.

Huang, C.-T. James. 1987. "Existential Sentences in Chinese and (in)definiteness." The Representation of (In)definiteness ed. by Eric. J. Reuland and Alice G. B. ter Meulen,

Af, 226-53. Cambridge, Mass.: MIT Press.

Huang, Lillian Meei-jin and Milip W. Davis. 1988. "Remarks on the semantics of word order in Mandarin Chinese." Paper presented to the 21 st International Conference on Sino-Tibetan Languages and Linguistics, Oct. 6-9, 1988, Lund, Sweden.

Kuno, Susumu. 1972. "Functional sentence perspective." Linguistic Inquiry 3.269-320.

Kuno, Susumu. 1987. Functional Syntax: Anaphora, Discourse, and Empathy. Chicago: University of Chicago Press.

Lambrecht, Knud. 1986. Topic, Focus, and the Grammar of Spoken French. PhD. dissertation, UC Berkeley.

Lambrecht, Knud. 1987. "Sentence focus, information structure, and the thetic-categorial distinction." Proceedings of the 13th Annual Meeting of the Berkeley Linguistic, Society, 366-82. Berkeley: Berkeley Linguistics Sociely.

Lambrecht, Knud. 1988. "There was a farmer had a dog: Syntactic amalgams revisited."

1.'Proceedings of the 14th Anmual Meeting of the Berkeley Linguistics Society. Berkeley: Berkeley Linguistics Socicty.

Lambrecht, Knud. 1989. "When subjects hehave like objects: $\wedge$ markedness analysis of sentence focus constructions across languages." (Revised and expanded version of 1987 LSA paper). ms. University of Texas al Austin. 
Lambrecht, Knud. To appear. Information Structure and Sentence Form. Cambridge: Cambridge University Press.

Lalolla, Randy J. 1990. "Grammatical Relations in Chinese: Synchronic and Diachronic Comsiderations." UC Berkeley M.D. dissertation.

LaPolla, Randy J. In preparation. "Semantic änd Pragmatic Principles in the Organization of Chinese Discourse." ms. Institute of History and Philology. Academia Sinice Taipei.

Li, Charles N., ed. 1976. Subject and Topic. New York: Academic Press.

$\mathrm{Li}$, Charles N, and Sandra $\Lambda$. Thompson. 1974a. "Chinese as a topic-prominent language." Paper presented to the 7 th International Conference on Sino-Tibetan Languages and Linguistics, Atlanta, Georgia, Oct. 18-19, 1974.

1.i, Chatles $N$, and Sandra $A$. Thompson. 1974b. "Coverbs in Mandarin Chinese: Verbs prepositions?" Joumal of Chinese Linguistics 2.257-278.

Li. Charles N. and Sandra $\Lambda$. Thompson. 197.5. "The semantic function of word order: $A$ case study in Mandarin." Word Order and Word Order Change ed. by Charles N. Li 163-96. Austin: University of Texas Press.

Li, Charles N. and Sandra A. Thompson. 1976, "Subject and topic: A new typology language." $\mathrm{C}, \mathrm{N}, \mathrm{Li}, \mathrm{cd}, 1976.459 .89$.

Li, Charles $N$. and Sandra $\Lambda$. Thompson. 1978. "Grammatical relations in languages without grammatical signals." lroceedings of the $12 \mathrm{th}$ International Congress of Lin guis/s ed. by Wolfgang Dressler, 687-91. Innsbruck: Innsbrucher Beiträger zur Sprachwissenschaft, Universität lunsbruck.

Li, Charles N. and Sandra $\Lambda$. Thompson. 1981. Mandarin Chinese: A functional reference grammar. Berkeley: University of California Press.

Li. Linding. 1986. "Shoushi Chengfen Ju Leixing Bijiao ( $A$ comparison of sentence types with affected (patient) elenents)." Zhongguo Viwen 1986.341-52.

McCawley, James D. 1988. "Notes on Li and Thompson 1981." Joumal of the Chinese Language Teachers Association. 24.19-42.

Mullic, Joseph. 1932. The Structural Principles of the Chinese Language. English translation by $A$. C. Versichel, 2 vols. Peking.

Nichols, Johanna. 1988a. "On SOV word order in Mandarin." ms. U. C. Berkeley.

Nichols, Johanna, 1988b. "On alienable and inalienable possession." In Honor of Mary Haas: From the Haas Festival Conference on Native American Linguistics ed. by William Shipley, 557-609. Berlin: Mouton de Ciruyter.

Prince, Ellen F. 1978. "A comparison of $W / h$-clefts and $/ 1$-clefts in discourse." Language 54.883 .906

Prince, Ellen F. 1981. "Toward a taxonomy of given-new information." Radical Pragmat ics ed. by Peter Cole, 223-55. New York and London: Academic Press.

Sasse, Hans-Jürgen. 1981. "Basic word order" and functional sentence perspective in Boni." Folia Linguistica 15.253 .90 .

Sasse, Hans-Jïrgen. 1984. "The pragmalics of noun incorporation in Eastern Cushitic Languages." Objects: Towards a theory of grammatical relations ed. by Frans Plank, 243-68. London: Academic Press.

Sasse, Hans-Jürgen. 1987. "The thetic/categorical distinction revisited," Linguistic 25.511 .80 .

Sun, Chao-fen. 1988. "The discourse function of numeral classifiers in Mandarin Chinese." Jourmal of Chinese Linguistics 16.298-321.

Sun, Chao-fen and T. Givón. 1985. "On the so-called SOV word order in Mandarin Chinese: A quantified text study and its implications." Language 61.329-51.

Sun. Hongkai. 1982. "Zang-Mianyu Ruogan Yinbian Tanyuan (On the origin of several sound changes in Tibeto-Burman)," Zhongguo Yuyanxuebao 1.269-98.

Tai, James H-Y. 1973. "Chinese as an SOV Language." Papers from the Ninth Regional Meeting of the Chicago Linguistics Society, 659-671. Chicago: Chicago Linguistics Society.

Teng, Shou-hsin. 1973. "Scope of negation." Jourmal of Chinese Linguistics 1.475-78.

Teng. Shou-hsin. 1974. "Double nominatives in Chinese." Language 50.455-73.

Teng. Shou-hsin. 1975. A Semantic Study of Transitivity Relations in Chinese. Berkeley and

Los Angeles: University of California Press.

Teng, Shou-hsin. 1979. "Remarks on cleft sentences in Chinese." Journal of Chinere 1. Linguistics 7.101-14.

Teng, Shou-hsin. 1985. "Gongneng Yufa yu Hanyu Xinxi Jiegou (Functional grammar and information structure in Chinese)." Procectings of the First International Conference on the Teaching of Chinese as a Scond langutuge, 164-68. Thipei: World Chinese Language Association.

Tsao, Feng-fu. 1979. A Functional Study of Topic in Chinese: The first step towards discourse analysis. Taihei: Student Book Co.

Tsao, Feng-fu. 1987. "A Topic-Comment Approach to the txi Construction." Journal of Chinese Linguistics 15.1-54.

Van Valin, Rohert D., Jr. 1975. "Existential lecatives in Mandarin." Paper presented to the 8th International Conference on Sino-Tibetan Languages and Linguistics, October 2426, 1975, U. C. Berkeley.

Van Valin, Robert D., Jr. 1984. "A typology of syntactic relations in clause linkage." Proceedings of the 10th Annual Mecting of the Berkeley Linguistics Society, 542-58. Berkeley: Berkeley Linguistics Society.

Van Valin, Robert D., Jr. 1993. " $A$ synopsis of Role and Reference Grammar." Advances in Role and Reference Grammar. ed. by Robert D. Van Valin, Jr, 1-166. Amsterdam/ Philadelphia: John Benjamins.

Wang. Liaoyi. 1982. Hany" yufa gangyoo (Outline of Chinese grammar). (With notes by A.A. Dragunov). Shanghai: Shanghai Jiaoyu Chubanshe.

Wang, Mingquan. 1988. "Comments on Sun and Givón's study of the OV constructions in Mandarin." Joumal of the Chinese Langunge Tencher's Association 23.33-53.

Xu, Yulong. 1987. "A study of referential functions of demonstratives in Chinese discourse." Joumal of Chinese Linguistics 15.132-151.

Zhu, Dexi. 1982. Yufa Jiangyi (Lecture notes on grammar). Beijing: Shangwu Yinshuguan. 